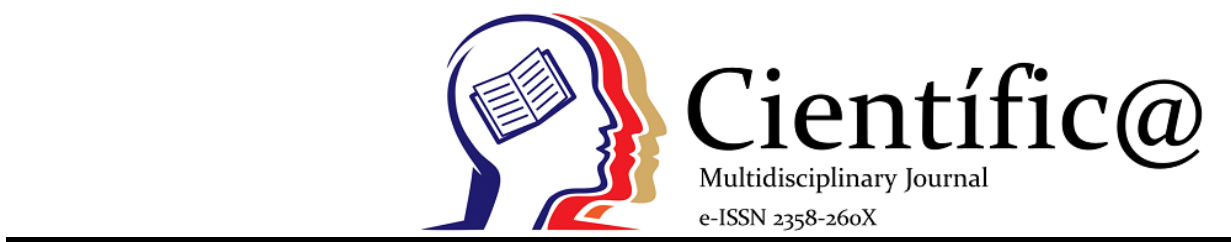

\title{
CRIANÇAS E ADOLESCENTES AUTORES DE ATO INFRACIONAL E SUBJETIVIDADE: DESAFIOS DA PRÁTICA PROFISSIONAL DE PSICOLOGIA
}

\author{
CHILDREN AND ADOLESCENTS AUTHORS OF INFRACTIONAL ACT AND SUBJECTIVITY: CHALLENGES \\ IN PROFESSIONAL PSYCHOLOGY PRACTICE
}

\author{
Geovana Soares Bolentine ${ }^{1}$, Pedro Otoni Ribeiro Costa ${ }^{2}$, Jéssica Batista Araújo ${ }^{3}$
}

${ }^{1}$ Acadêmico, Universidade Evangélica de Goiás - UniEVANGÉLICA, Departamento de Psicologia.

${ }^{2}$ Professora mestra, Universidade Evangélica de Goiás - UniEVANGÉLICA, Departamento de Psicologia;

\section{Info}

Recebido: 05/2021

Publicado: 06/2021

DOI: $10.37951 / 2358-260 X .2021 v 8 i 1.5863$

ISSN: 2358-260X

\section{Palavras-Chave}

ato infracional, crianças e adolescentes,

psicologia, subjetividade

Keywords:

infraction, children and adolescents,

psychology, subjectivity

\section{Resumo}

A sociedade moderna tem enfrentado um pânico social crescente em que a mídia espalha as taxas de crimes e violência de maneiras sensacionalistas pelos meios de comunicação. Nesse contexto, estão envolvidos no "mundo do crime", os adolescentes autores de atos infracionais, que são atos contrário às normas, sendo ilegal e julgado por lei, como consta no Estatuto da Criança e do Adolescente (ECA). É de extrema preocupação as situações dos jovens em conflito com a lei, principalmente no que tange às práticas dos profissionais de psicologia para modificar essa realidade. Há uma tendência política e social de intervir na substância do problema sem investigar sua causa raiz, acreditando que sua solução só é alcançada por meio de leis e decretos, separados das necessidades das crianças $e$ adolescentes no Brasil. Pretende-se problematizar as questões relacionadas à prática profissional dos psicólogos neste contexto; compreender o papel da psicologia na reinserção social das crianças e adolescentes em medidas socioeducativas e fatores de reincidência. Mapear e rastrear os principais textos sobre o tema; buscar analisadores na história; analisar e construir mapas das relações de poder e esquema de forças; traçar diagramas; problematizar objetos e práticas. $A$ metodologia utilizada é a cartografia, método postulado por Deleuze e Guattari (1995) na introdução do livro Rizoma: esquizofrenia e capitalismo e parte de um novo entender sobre o pesquisar. Nesse trabalho, tecemos dois diagramas desenrolando suas linhas de força, poder/saber e buscando as linhas de fuga, de resistência - talvez o grande desafio da psicologia nesse campo.

\begin{abstract}
Modern society has faced a growing social panic in which the media spreads crime and violence rates in sensational ways across the media. In this context, adolescents are involved in the "world of crime", the perpetrators of infractions, which are acts contrary to the rules, being illegal and judged by law, as stated in the Statute of Children and Adolescents (ECA). The situations of young people in conflict with the law are of extreme concern, especially with regard to the practices of psychology professionals to change this reality. There is a political and social tendency to intervene in the substance of the problem without investigating its root cause, believing that its solution is only achieved through laws and decrees, separate from the needs of children and adolescents in Brazil. It is intended to problematize the issues related to the professional practice of psychologists in this context; understand the role of psychology in the social reintegration of children and adolescents in socio-educational measures and recidivism factors. Map and track the main texts on the topic; look for analyzers in history; analyze and build maps of power relations and forces scheme; draw diagrams; problematize objects and practices. The methodology used is cartography, a method postulated by Deleuze and Guattari (1995) in the introduction of the book Rizoma: schizophrenia and capitalism and part of a new understanding of research. In this work, we weave two diagrams unraveling their lines of force, power/knowledge and looking for lines of flight, of resistance perhaps the greatest challenge for psychology in this field.
\end{abstract}

\section{INTRODUÇÃO}

A violência é uma

contemporaneidade a partir de políticas e investimentos, apontando suas dimensões, tanto micropolítico quanto macropolítico, mas sobretudo por 
aquilo que não podemos ignorar no nosso presente (Huning, Bernardes \& Reis, 2019).

De acordo com Segalin e Trzcinski (2006), a sociedade moderna tem enfrentado um pânico social crescente em que a mídia espalha as taxas de crimes e violência de maneiras sensacionalistas pelos meios de comunicação. Nesse contexto, estão envolvidos no "mundo do crime", as crianças e adolescentes autores de atos infracionais, que são atos contrários às normas, sendo ilegal e julgado por lei, como consta no Estatuto da Criança e do Adolescente (ECA).

Ainda segundo Segalin e Trzcinski (2006), com a promulgação da Constituição Federal de 1988, por meio da Lei Federal n ${ }^{\circ}$ 8.069/90 - o Estatuto da Criança e do Adolescente (ECA) - conforme os princípios da Convenção das Nações Unidas sobre os Direitos da Criança e os artigos 227 e 228 da Constituição Brasileira, simboliza a transição para os direitos juvenis, validando o conceito de proteção integral ao direito juvenil brasileiro, permitindo o reconhecimento e ingresso das crianças e adolescentes no Estado Democrático de Direito, igualando-se ao cidadão adulto, mas protege sua idade e capacidade, principalmente as características de população em desenvolvimento.

Pode-se considerar o surgimento do ECA como um acontecimento. Um daqueles momentos de virada do dispositivo da infância, que são singulares e históricos. Essa reconfiguração do dispositivo é resultado de um emaranhado de linhas de poder/saber que, como em um campo de batalha, buscam vitória e seu momento sobre os holofotes - afinal como nos explicou Deleuze (1995), um dispositivo é uma máquina de fazer ver e falar, fazendo nascer ou desaparecer objetos.

Foucault nos pergunta "O que é a nossa atualidade?", e ao fazer isso retoma a noção de acontecimento como característica desta interrogação.
Foucault ainda traz que interrogar a atualidade é fazer questionamento como acontecimento e assim, problematizá-la (Cardoso, 1995). Deste modo, acontecimento força o pensamento, e certamente esse acontecimento, a entrada em cena do ECA, nos instiga a perguntar e investigar quais os novos discursos e práticas sobre a infância? Quais sujeitos foram produzidos por esse dispositivo?

O ECA foi um momento de inversão de forças. A partir daí começam a surgir novos discursos, novas verdades, novas práticas, novos sujeitos começaram a se constituir, como as crianças e adolescentes que passaram a ser entendidas como sujeitos de direitos, surgindo novas organizações que começam a produzir novos sujeitos.

Conforme Moreira e Costa (2016) embora os direitos civis tenham sido previamente anunciados no ECA e o Estado tenha a obrigação de garantir, respeitar, promover e proteger esses direitos, nas atuais circunstâncias existe um descompasso entre o conteúdo da legislação e a aplicação dos poderes, principalmente por parte do Executivo. Nesse sentido, deve-se enfatizar que a atualização dos dispositivos formais no ECA depende diretamente da chamada política pública, ou seja, dos planos e serviços formulados e implementados pelo Estado.

Se partimos das lições de Hannah Arendt (1998, citado por Moreira \& Costa, 2016), a política atual definida como a confusão entre poder estatal e gestão administrativa pode ser considerada apolítica. É válido lembrar que, para a filósofa, a política pressupõe a participação ativa dos cidadãos nas decisões do Estado, enquanto a gestão administrativa transfere os indivíduos, reduzindo-os à objeto das decisões.

Volpi (2001, cit. por Segalin \& Trzcinski, 2006) acrescenta que o ECA legitima e assegura a existência de um indivíduo político e social, ou seja, prioriza crianças e adolescentes, independentemente de sua 
condição social ou econômica, raça, religião e cultura. A Doutrina de Proteção Integral sugere que os direitos dos jovens devem ser concedidos a todas as crianças e adolescentes sem distinção.

Além do ECA, a Lei $\mathrm{n}^{\circ}$ 12.594/2012 implementa o Sistema Nacional de Atendimento Socioeducativo (SINASE) em que Lazzarotto (2014) define como:

Documento que trata de um conjunto de princípios, regras e critérios de caráter jurídico, político, pedagógico, financeiro e administrativo, envolvendo o processo de apuração do ato infracional, a execução da medida socioeducativa e os modos de gestão, avaliação e controle social. (Lazzarotto, 2014, p.504).

Conforme Guerra, Cunha, Costa e Silva (2014), no decorrer da apreensão do menor infrator e, após a realização dos procedimentos legais, o juiz da Vara da Infância e da Juventude pode efetuar uma das medidas socioeducativas contidas no ECA: advertência, responsabilidade pela reparação de avarias, internação em instituição socioeducativa, serviço comunitário, liberdade assistida e semiliberdade. Dessa forma, os profissionais de psicologia que exercem função neste tipo de atendimento devem reformular suas práticas de acordo com as medidas preconizadas pelo ECA: responsabilidade pela conduta criminosa e reinserção social e familiar (Guerra et al., 2014).

O presente Trabalho de Conclusão de Curso tem como tema Crianças e adolescentes autores de ato infracional e subjetividade: desafios da prática profissional de psicologia. Pretende-se mapear ou cartografar as práticas e saberes da psicologia no contexto das crianças e adolescentes autores de ato infracional, seus agenciamentos e problemáticas envolvidas nos processos históricos a partir das ferramentas conceituais deleuzianas e foucautianas, afim de realizar um diagnóstico do presente sobre as práticas psicológicas nesse contexto.

É de extrema preocupação as situações dos jovens em conflito com a lei, principalmente no que tange às práticas dos profissionais de psicologia para modificar essa realidade. Há uma tendência política e social de intervir na substância do problema sem investigar sua causa raiz, acreditando que sua solução só é alcançada por meio de leis e decretos, separados das necessidades das crianças e adolescentes no Brasil (Segalin \& Trzcinski, 2006).

Assim, constituído por 267 artigos, o ECA tem, em princípio, a prioridade absoluta das crianças e adolescentes, no que se refere ao disposto no art. 227 da Constituição Federal. De forma simplificada, podese dizer que o Estatuto reflete a Constituição e expressa um compromisso intergeracional, pautado na lógica de que a situação futura de um país está diretamente relacionada à preocupação com a qual se dedica à infância e à adolescência. No entanto, apesar da aplicação avançada dos direitos dos cidadãos consagrados no ECA e do compromisso do Estado de respeitar, proteger, garantir e promover tais direitos, o que está acontecendo no presente contexto é uma discrepância entre o que é promulgado por lei e o que é aplicado pelo governo, especialmente pelo executivo. Nesse sentido, cabe destacar que a especificidade dos dispositivos formais do ECA depende diretamente das chamadas políticas públicas, ou seja, dependem dos programas, projetos e serviços formulados e implementados pelo Estado (Moreira \& Costa, 2016).

De acordo com Michel Foucault (2004, cit. por Filho, 2015) a prisão é mais antiga do que os códigos que a estabelecem como liberdade condicional por 
excelência. Ela nasceu tão apegada aos mecanismos disciplinares que colonizaram o corpo social dos séculos XVII e XVIII que parecia o acontecimento natural do progresso da história.

A partir de análises dos estudos de Foucault, Filho (2015) diz que a prisão é o elo que combina dois mecanismos: um mecanismo é o estabelecimento da delinquência tanto como uma finalidade do exercício do poder quanto um objeto do campo de saber e outra que promove uma nova gestão de ilegalidade e a separa do crime. Na visão de Foucault (2004, cit. por Filho, 2015) a prisão é atravessada por mecanismos disciplinares que tornaram - e a tornam - um dos alicerces da produção capitalística.

No final do século XIX, com a industrialização, o surgimento da figura de um trabalhador "livre" que vendia o seu trabalho braçal e assim considerado digno dos pobres sob a égide utópica da "liberdade, igualdade e fraternidade", afirma Coimbra (2003, cit. por Dameda, 2017). Herança do tempo de lazer, conforme afirmado por Coimbra; Zamora; Frasseto, Costa e Cerqueira (2003;2008;2015, cit. por Dameda, 2017) e outros autores, as crianças e adolescentes pobres eram conforme descrito anteriormente, menores de idade; $\mathrm{O}$ uso do termo "menor" não se referia aos menores entre as quais as classes sociais, mas apenas para distinguir um determinado segmento: os pobres (Coimbra, 2003, cit. por Dameda, 2017). Estes que tivessem que ser removidos da vida familiar e colocados em "instituições correcionais", onde muitas vezes viviam em condições precárias e na violência disciplinar - trata-se de uma medida protetora baseada no Código do Menor, criado em 1927, que enfatizava a responsabilidade individual pelo ato. Movimentos de trabalhadores surgidos em 1980, para garantir certos direitos no Brasil, levaram a iniciativas de um suposto sistema de proteção social, amparado em contribuições e voltado para os mais pobres, estabelecendo relações de clientelismo e filantropia - também como forma de controle sobre trabalhadores.

Com isso, a expressão menor foi primeiramente citada no Brasil no código criminal do império com a finalidade de estabelecer as penas nos casos de crimes cometidos "por menores de idade". Ao final do século XIX a expressão migrou do jurídico para o social, passando a representar crianças das gradações mais baixas da pirâmide social. Do jurídico ao social, assume-se sentido de controle, ou seja, ao seccionar setores sociais, cria-se conjuntos de crianças classificadas como "suspeitas", "possivelmente perigosas" na junção entre o perigo e a pobreza (Santos, 2011).

No Brasil, famílias da elite econômica e intelectual foram cooptadas e formadas por meio de discursos médicos-pedagógicos que as identificam com os ideais de conduta que pretendem perseguir. Isso afetou os segmentos mais pobres da população de diferentes maneiras, com seu comportamento sendo capturado e seus corpos controlados pela polícia e registros legais. Ainda de acordo com o autor, ao longo do século XX, o termo "menor" atendeu à necessidade de distinguir entre o bem-nascido e potencialmente perigoso para a sociedade, fazendo a diferença entre crianças e menores indocumentados, atribuindo o risco social de quebra da ordem. Devido às ameaças que revelaram, menores foram sistematicamente hospitalizados, afastados das suas famílias e as crianças - que foram colocadas em grandes internatos no século XIX - começaram a educar-se a partir dos núcleos familiares primários (Donzelot, 1986, cit. por Santos, 2011).

Segundo a análise de Foucault (2002, citado por Santos, 2011), entendemos que a psicologia se constitui 
como um discurso e, como tal, é estritamente dependente do campo sociopolítico em que se insere. Nesta perspectiva, e emergência do discurso psicológico surge como um evento possível na composição das forças constituintes do mundo moderno.

No Brasil, a ideia original de "psi” está relacionada à experiência do direito e da prática judiciária, seja no universo da tipificação louco/criminoso nas primeiras décadas do século passado, seja na classificação e exame de "menores" por psicólogos logo após a promulgação da primeira lei de menores em 1927. Manifestando ambições científicas desse período de conhecer o homem e a sociedade, a psicologia serviu para distinguir o indivíduo "normal" e controlar o "desviante". Considerando que o saber psicológico faz parte do discurso do ser humano na sociedade moderna na história, é necessário considerar que a teoria e a prática psicológica participam ativamente da construção da realidade social que valoriza determinados comportamentos e negam outros. Em outras palavras, pensar que a psicologia se constitui pelo discurso do campo sociopolítico é bem diferente de pensar que o conhecimento psicológico representa a verdade sobre o sujeito (Santos, 2011).

Nesta perspectiva, o presente projeto de pesquisa busca analisar as práticas da psicologia neste contexto. Como ela se insere e contribui para a produção de práticas delinquentes? Quais as potencialidades dessas práticas psicológicas nesses contextos pra criar outros territórios existenciais, criando linhas de fuga aos saberes/poderes disciplinares?

Temos como objetivos problematizar as questões relacionadas à prática profissional dos psicólogos em relação às crianças e adolescentes autores de ato infracional; compreender o papel da psicologia na reinserção social das crianças e adolescentes em medidas socioeducativas e fatores de reincidência. Mapear e rastrear os principais textos sobre o tema; buscar analisadores na história; analisar e construir mapas das relações de poder e esquema de forças; traçar diagramas; problematizar objetos e práticas.

De acordo com Filho (2015) entre os séculos XVIII e XIX, a punição tornou-se uma função do crime e, portanto, dar-lhe o direito de punir todas as pessoas que tenha violado as regras do contrato social. Neste momento da história, a prisão tornou-se a ferramenta básica do direito penal. O momento em que a justiça se recusa a tocar no corpo da pessoa condenada em vez de punir seu corpo, se limita a privá-lo de seus interesses e direitos mais importantes: a liberdade. Como escreveu Foucault (2004, cit. por Filho, 2015), a entrada da justiça penal à "humanidade".

Assim, no final do século XVII e início do século XVIII, uma nova economia foi inaugurada aos mecanismos de poder, como relatado por Foucault (2001, cit. por Filho, 2015), por meio de procedimentos, análises que permitem aumentar os efeitos do poder, reduzir os custos de seus exercícios e integrar o exercício do poder aos mecanismos de produção. Em outras palavras, desde o século XVIII, os mecanismos de poder atuarão mais por meio de rituais de punição às pessoas, com monitoramento contínuo e tecnologia de controle de instituições sociais inteiras. O exercício deste poder deixará de estar sujeito à vontade do soberano, mas será restringido por lei, aplicável a todas as situações quando necessário, sem qualquer diferença (Filho, 2015).

No Brasil, muitas instituições de internação prevalecem em condições físicas superlotadas, condições anti-higiênicas e conceitos de construção que não atendem ao Estatuto da Criança e do Adolescente - ECA; não há orientação metodológica - orientação operacional clara e de rotinas. Além disso, existem situações mais graves, como tortura física e psicológica, 
abuso sexual, isolamento e não comunicação, incluindo as mais diversas manifestações de violência e humilhação, supermedicalização como mecanismo de docilização do corpo adolescente (Conselho Federal de Psicologia, 2010).

$$
\text { Conforme o CFP (2010) as práticas }
$$

socioeducativas assentam num padrão institucional de convivência que exige organização do cotidiano, regras e rotinas, formas produtivas de passar o tempo (educativo, terapêutico, cultural, recreativo, desportivo) num ambiente físico saudável e onde as necessidades de sono, alimentação, higiene, saúde e escolarização sejam garantidas.

No entanto, a prisão é resultado de um procedimento iniciado no século XIV, ao criar dispositivos para isolar e controlar classes marginalizadas, mais razões para sua existência devem ser buscadas no desenvolvimento de dispositivos disciplinares, ao invés no âmbito da nova regulamentação que estabelece o seu papel na nova economia punitiva. Portanto, desde o seu surgimento, as prisões tornaram-se uma ferramenta para restringir e reformar os indivíduos nas prisões (Filho, 2015). Se mais tarde, nos séculos XVIII e XIX, ela se tornou uma ferramenta para resistir às sansões penais severas, é porque tem suas vantagens para o capitalismo e a lógica disciplinar.

De acordo com Filho (2015), a prisão produz um item que deve, se não lutar, pelo menos desligá-la. Ainda segundo o autor, se a justiça agradece aos filhos ilegítimos nascidos na união entre prisão e custódia, é porque, logo que crescem, se descobriu o quanto podem, pela mesma justiça, serem úteis.

Segundo Foucault (2004, citado por Filho, 2015), a prisão não falha, pelo contrário, cumpre perfeitamente o papel que foi designado pela sua sociedade disciplinar, nomeadamente criar uma classe de criminosos que atuam principalmente na nova gestão de fenômenos sociais ilegais; que permite que a classe dominante se divida entre o povo e os criminosos, separando e confiando ao primeiro também aceitou a ética estrita e estabeleceu uma força policial cuja existência será legitimada pela aceitação das pessoas do perigo em que correm.

Segundo Filho (2015) a prisão é o elo que une dois mecanismos: um constitui crime não apenas como o objetivo de exercer o poder, mas também o objeto do poder; outra promove nova gestão de atos ilícitos e os vincula a delinquência. Como escreveu Foucault (2004, citado por Filho, 2015), produzindo atos ilegais, obviamente marginalizados, mas sob controle central; produzindo criminosos como sujeito patológico.

"Prisão" e "lógica totalitária" é uma técnica que é aprendida, transmitida e segue as regras gerais. A técnica disciplinar tornou-se conhecimento e escola. Este é o limiar diferenciador que surge, então, na Psicologia Científica, com os profissionais de disciplina, sujeição e normalidade (Benelli, 2014).

Hospitais, escolas, oficinas, fábricas, quartéis, prisões e policiais são colonizados por essas disciplinas e transformados em equipamentos diversos. De acordo com Benelli (2014) nesses equipamentos, qualquer mecanismo de objetivação produzirá subjetividade, e qualquer aumento de poder produzirá conhecimentos possíveis, como: racionalização da medicina clínica, psicologia infantil, psicopedagogia, criminologia, trabalho industrial. As técnicas de exame são a base para o surgimento das ciências humanas: psicologia, sociologia, estatística, educação, psiquiatria e criminologia. Um novo tipo de força pode produzir novos conhecimentos. A tecnologia da fiscalização disciplinar foi invadida de forma insidiosa, como se por baixo, em princípio, ainda fosse curiosa a justiça penal (Benelli, 2014).

Como diz Foucault (1999, citado por Benelli, 2014) o "delinquente" é visto como o objeto da 
criminologia em que permite a constituição, por meio da Medicina e da Psicologia, um sujeito no qual se sobrepõem grosseiramente. Temos aí então, a produção de sujeitos das relações entre saberes e poderes em um contexto institucional específico (Benelli, 2014).

Quando pensamos em "políticas públicas" em relação às práticas violentas, principalmente em relação aos jovens, é necessário reconhecer a trajetória histórica de compreensão e prática para esse público, ainda presente nas complexidades da modernidade.

Inicialmente, Coimbra (2003, cit. por Dameda, 2017) é usado para descrever essas teorias racistas europeias do século XIX e condenou as misturas raciais que os tornavam indesejáveis e estabelecer um padrão de modos de ser - subjetividade. A autora sustenta que, segundo o capitalismo, ser destituído significa ser livre; assim, o pobre sujeito, que negava a condição disciplinar do trabalho, era considerado sem vontade, sem moralidade nem inteligência e, portanto, perigoso porque nenhuma entidade religiosa poderia mudar isso. A autora aponta que a ciência moderna surgiu para confirmar a natureza perversa dos pobres súditos e buscar evidências de inferioridade em relação à classe dominante.

Coimbra (2003, cit. por Dameda, 2017) cita que a própria teoria darwiniana, cunhada no século XVIII, contribuiu para a ideia de que o pobre nasce perigoso porque possui uma herança degenerativa; ou seja, uma pessoa nascida em um ambiente pobre sempre teria dúvidas porque era descendente de pais astutos, sendo potencialmente criminoso.

Todos os que não eram corpos submissos e úteis à produção tiveram que ser exterminados (Coimbra, 2003, cit. por Dameda, 2017), por volta de 1920, o movimento higienista - uma prática considerada desinfetante e civilizador pretendia erradicar a pobreza para criar uma sociedade moderna. Tais teorias e práticas surgiram como uma forma de conhecer e tomar medidas de proteção para explicar os problemas sociais, bem como justificar o fim desta "raça".

Soma-se a isso a imagem da indiscutibilidade como permissão e não como punição para os adolescentes que cometeram um crime. Segundo Miraglia (2005, citado por Moreira, Guerra, Oliveira, Souza \& Soares, 2015), a ação penal é moldada por valores sociais que permeiam o ambiente do julgamento e, portanto, o universo dos juízes. Ao questionar o espaço com os aspectos técnicos da aplicação da lei, eles criam um ritual discriminatório que aborda estereótipos e preconceitos.

Na linha analítica de Minahim e Sposato (2011, cit. por Moreira \& Costa, 2016) assumem que negar a natureza criminosa das medidas socioeducativas e referir-se deliberadamente à educação e proteção como seus únicos objetivos contribui para o uso massivo da medida de internamento - que em muitos casos não seria aplicável - unicamente ao caráter privado e, portanto, criminal dessas medidas. Assim, as atividades socioeducativas não são um instrumento de reinserção social, mas sim um instrumento de dupla exclusão desses adolescentes.

Segundo Balaguer (2005, cit. por Moreira \& Costa, 2016), a privação de direitos também ocorre no caso de contravenções adolescentes, de duas formas, primeiro, em termos de privação da vida pública e política por falta de direitos fundamentais; e, segundo, condenando e aderindo a medidas socioeducativas que continuem preservando o caráter repressivo, brutal e punitivo do Código do Menor. Assim, a violência dos atos transgressivos da adolescência foi posta como uma resposta ao estado de barbárie gerado por uma sociedade desigualmente dividida pelo "mal-estar civilizatório" (Freud, 1930, cit. por Moreira \& Costa, 2016).

Minahim e Sposato (2011, cit. por Moreira \& Costa, 2016) constataram na análise das medidas de 
detenção implementadas pelos tribunais que a implementação de tais medidas é baseada nas circunstâncias pessoais dos jovens, não com base em tomar medidas ilegais e usar argumentos como desordens sociais e morais, tendências violentas, riscos a terceiros, desvios de personalidade e insuficiência ambiental como justificativas para tais ações de medidas de detenção e mostrar estereótipos dos jovens condenados.

\section{METODOLOGIA DA PESQUISA}

A metodologia utilizada é a cartografia, método postulado por Guattari e Deleuze ([1995] 2011) na introdução do livro Rizoma: esquizofrenia e capitalismo e parte de um novo entender sobre o pesquisar. A cartografia se dará partir da cartografia bibliográfica. De acordo com Dameda (2017), pesquisar está relacionado ao desejo, a uma busca pelo saber, que não emergem (in)verdades, mas olhares que têm direção de acordo com quem pesquisa. E, nessa perspectiva, Miranda e Mourão (2016, citado por Dameda, 2017) afirmam que a pesquisa se forma no "entre" (pesquisador adolescentes - contextos), um entre composto por práticas discursivas e não discursivas e que não estabelece uma totalidade fechada, portanto, pesquisar é colocar em evidência alguns "entrecruzamentos" que surgem numa dimensão de processos.

A cartografia está relacionada aos campos do conhecimento das ciências sociais e humanas e trata não apenas do mapeamento físico, mas também dos movimentos, relações, jogos de poder, confrontos de poder, lutas, jogos de verdade, enunciados, modos de operação, objetivação, subjetivação, estetização de si mesmo, práticas de resistência e liberdade (Filho \& Teti, 2013).

De acordo com Filho e Teti (2013) essa estratégia não desenha mapas no sentido tradicional do termo, mas sim diagramas que não se referem à topografia, mas sim à topologia dinâmica, movimentos e locais de poder, desenha diagramas de poder, traça linhas de força, intensidades, densidades e enfrentamentos.

Conforme Deleuze (1988, citado por Filho \& Teti, 2013) os diagramas não são documentos auditivos ou visuais, mas mapas, cartografia e estendem-se a todo o campo social. É uma máquina abstrata. Ele se define pela função e informa a matéria, ignora qualquer diferença formal entre conteúdo e expressão, forma discursiva e não discursiva. Embora seja algo que permite ver e falar, é quase uma máquina silenciosa e cega.

A cartografia tornou-se um dos princípios do rizoma (Deleuze \& Guattari, 1995, citado por Zambenedetti \& Silva, 2011). Os rizomas se ramificam em mais direções e crescem de acordo com as conexões estabelecidas que conectam qualquer ponto a qualquer outro ponto. Portanto, o rizoma é caracterizado por uma rede não hierárquica, que não existe início nem fim, podendo derivar infinitamente, estabelecer conexões horizontais sem poder centralizá-lo ou circundá-lo. O rizoma está sempre no meio entre as coisas, criando novas e múltiplas combinações (Guattari \& Rolnik, 1986, citado por Zambenedetti \& Silva, 2011).

Deleuze (2005, citado por Filho \& Teti, 2013) cita que a cartografia é um método para desmaranhar as linhas de um dispositivo. No conceito de Foucault (1984, citado por Filho \& Teti, 2013), dispositivo está sempre incluído no jogo de poder, mas está sempre associado a um ou às configurações de saberes que dele nascem. São estratégias de relacionamento de poder manter e ser sustentado por tipos de conhecimentos.

Nesse trabalho, tendo como objeto as Crianças e adolescentes autores de ato infracional e subjetividade tecemos dois diagramas desenrolando suas linhas de força, poder/saber e buscando as linhas de fuga, de 
resistência - talvez o grande desafio da psicologia nesse campo.

\section{REVISÃO TEÓRICA}

\subsection{Diagrama da Justiça Retributiva}

Neste diagrama será abordado sobre a Justiça Retributiva, que é um modo de concretizar a punição aos infratores, relacionando com o poder disciplinar postulado por Michel Foucault em que foram observadas_nas práticas das prisões, trazendo também a construção da categoria menor, a problematização das práticas nos contextos das medidas socioeducativas e as novas discussões sobre a redução da maioridade penal.

O objetivo da justiça retributiva é a punição do infrator, desconsiderando o efeito de retribuir o mal do crime com o mal da pena. Eliminando-se a conciliação, transação e mediação, sustendo que o delito é uma afronta à sociedade (Kontoyanis, 2018).

Independente dos fatores econômicos e sociais envolvidos, o indivíduo infrator sempre será o culpado pelos atos.

Ainda segundo Kontoyanis (2018) na justiça retributiva, a vítima é apenas o informante, não faz parte do processo. A existência dela é registrada apenas para informar que o fato aconteceu, sem sequer testemunhar. Em ações públicas incondicionais, ela não tem o direito de falar, nem de decidir o que pode ou não pode acontecer aos criminosos. Por outro lado, sua voz não é ouvida no sentido de suas necessidades, ansiedade, medos e desejos. Ou seja, em retribuição, as vítimas, criminosos, sem falar nos interesses e necessidades da comunidade não são mostrados.

O processo não garante a assistência psicossocial adequada ou até mesmo jurídica, tende a alienar a vítima de seu curso e voltar os atos apenas para o réu da ação.

$\mathrm{Na}$ justiça retributiva prepondera o interesse do Estado, tendo como foco a punição, prisão ou outra punição simbólica, culpa pessoal e uso dogmático da lei. Os procedimentos são formais, com cenário de Poder e ritualístico, regras técnicas e linguagens complexas na ótica jurisdicional (Kontoyanis, 2018).

De acordo com Kontoyanis (2018) possui ainda as seguintes perspectivas: para a vítima, participação mínima, assistência psicossocial e jurídica mínima, frustração e insatisfação com o sistema. Para o ofensor, absorto do processo, comunicação por meio do advogado, necessidades praticamente desconsideradas, inacessível e sem interação. Para a comunidade, polarização do infrator e vítima, percepção de ineficiência do sistema, ausência de paz social.

O modelo retributivo se assemelha ao que era proposto já no nascimento das prisões em que segundo Foucault (1999, cit. por Benelli, 2014) a prisão foi criada fora do judiciário quando foi desenvolvida à fim do corpo social, com o objetivo de realizar a divisão dos indivíduos, fixação, distribuição espacial e classificação, buscando maximizar seu tempo e força, treinando seus corpos, codificando constantemente seus comportamentos, mantendo-os visíveis sem lacunas, criando uma observação completa, registrando e anotando, produzindo conhecimento que acumula e centraliza. Antes que a lei a definisse como um castigo de excelência, a prisão foi criada na forma geral de um dispositivo que tornava o indivíduo dócil e útil ao realizar um trabalho preciso sobre o corpo humano (Foucault, 1987).

Em Vigiar e Punir, Foucault (1987) diz que a prisão é uma parte indispensável do castigo e, sem dúvida, marca um momento importante na história da justiça criminal: a aquisição da "humanidade". Porém, na história desses mecanismos disciplinares, um momento importante no desenvolvimento de novas forças de classe é o momento em que elas colonizaram o judiciário. 
O poder disciplinar é, na verdade, um poder com uma função maior de "treinamento", ao invés de apropriação e retirada. Ele não vincula o poder para reduzir o poder, ele se esforça para vinculá-los de modo que sejam multiplicados e usados como um todo. Não unifica e multiplica todo o conteúdo que lhe é submetido, mas decompõe, analisa, distingue e decompõe o processo em uma singularidade necessária e suficiente. Ele "treina" as massas caóticas, móveis e inúteis de corpos e forças, gerando assim múltiplos elementos individuais - pequenas células independentes, autonomia orgânica, identidade e continuidade genética, fragmentos combinados. A disciplina "faz" o indivíduo, é uma técnica específica de poder que usa o indivíduo como objeto e meio de seu exercício. Depender do excedente não é depender do próprio superpoder para conquistar o poder. É uma força moderada e suspeita que pode ser usada como uma operação econômica planejada, mas permanente. Se o comparar com o ritual soberano solene ou o grande paradigma do país, é uma forma modesta e menos procedimental. São eles que vão invadir gradualmente essas formas maiores, modificar seus mecanismos e impor seus processos a eles. O judiciário não vai conseguir escapar dessa intrusão, que é quase secreta. O sucesso da capacidade disciplinar deve-se, sem dúvida, ao uso de ferramentas simples: sansão normalizadora, olhar hierárquico e a combinação em um processo específico (exame) (Foucault, 1987).

Pode-se entender, sob a ótica de Foucault, que a prisão é uma ferramenta do poder disciplinar, que foi construído sob o exercício do poder de punir mediante limitação do tempo livre, castigo e isolamento - fatores que são vistos nas medidas de internação de crianças e adolescentes -. Ao estudar a origem da categoria menor no Brasil, nota-se que há presença dos preceitos contidos no nascimento das prisões, do poder disciplinar e também da justiça retributiva - ainda vigente atualmente -.

O Sistema Nacional de Atendimento Socioeducativo (SINASE) foi instituído na Lei $\mathrm{N}^{\circ}$ 12.594, de 18 de janeiro de 2012, no qual ao analisar suas diretrizes pode-se perceber no Art. $4^{\circ}$ em que compete aos Estados a obrigatoriedade de criar, desenvolver e manter programas para a execução das medidas socioeducativas de semiliberdade e internação.

\subsection{Construção da Categoria Menor}

Mesmo com as mudanças e promulgações de leis como as ocorridas com o ECA e o SINASE, é comum encontrarmos atualmente o termo menor sendo usado para designar as crianças e adolescentes por meio de reportagens, notícias jornalísticas expostas nos meios de comunicação. Vimos tais notícias nos principais jornais brasileiros como o G1, CNN Brasil, Jornal O Dia entre outros.

No Brasil moderno surgiu um termo que conceitua bem a criança desvalida: menor. Este termo foi inicialmente utilizado para designar uma faixa etária associada, pelo Código de Menores de 1927, às crianças pobres, passando a ter, posteriormente, uma conotação valorativa negativa. Metaforicamente, menores passaram a ser todos aqueles ao quais a sociedade atribuía um significado social negativo. Menores eram aquelas crianças e adolescentes pobres, pertencentes às famílias com uma estrutura diferente da convencional (patriarcal, com pai e mãe presentes, com pais trabalhadores, com uma boa estrutura financeira e emocional, dentre outros) (Frota, 2007).

Segundo Frota (2007) aquelas crianças caracterizaram-se como "menores" em situação de risco social, passíveis de tornarem-se marginais e, como marginais, colocarem em risco a si mesmas e à sociedade. Deste modo, tornou-se uma norma social atender à infância abandonada, pobre e desvalida, mas 
a partir de um olhar de superioridade, na tentativa de salvamento ou de "adestramento".

Ainda de acordo com a autora, o "menor" foi entregue à alçada do Estado, que tratou de cuidar dele, institucionalizando-o, submetendo-o a tratamentos e cuidados massificantes, cruéis e preconceituosos. Por entender o "menor" como uma situação de perigo social e individual, o primeiro código de menores, datado de 1927, acabou por construir uma categoria de crianças menos humanas, menos crianças do que as outras crianças, quase uma ameaça à sociedade.

Com a aprovação do Estatuto da Criança e do Adolescente, em 1990, o termo "menor" foi abolido, passando a definir todas as crianças como sujeito de direitos, com necessidades específicas, decorrentes de seu desenvolvimento peculiar, e que, por conta disso, deveriam receber uma política de atenção integral a seus direitos construídos social e historicamente (Frota, 2007).

A mudança é radical, vai à raiz: o menor deixa de ser visto como menor e retoma seu lugar de criança. O menor passa a ser visto como cidadão de direitos e não como um expectador das tentativas de sabê-lo vítima ou responsável pelos descalabros sociais. A criança volta a ocupar o seu lugar de um ser humano, de um sujeito construído historicamente, com direitos e deveres que devem ser exercidos hoje, com uma vida concreta que pode ser muito dura e distante do sonho dourado da infância mítica da classe média. Contudo, uma criança. (Frota, 2007)

Os impactos dos saberes que estavam sendo construídos sobre a infância, incluindo a pediatria, pedagogia dos pais e a influência da escola positiva de Cesare Lombrosso e suas concepções biodeterministas (depravação, transmissão hereditária, tendências criminosas e antissociais) faz-se de forma a distinguir filhos (filhos de familias ricas) e menores (filhos de pessoas pobres). Ela apoia e naturaliza a lógica do governo político por meio de preconceitos anormais, disfuncionais e de doenças (Santos, 2011).

Como já discutido por Donzelot (1986, cit. por Santos, 2011), a distinção entre as noções de criança e menor expressa origens de classe, sendo a infância uma construção claramente burguesa.

A pobreza está relacionada a certos grupos ou indivíduos: a preguiça, a indolência e os vícios eram inerentes aos pobres, de modo que a pobreza que os cercava resultava de sua preguiça e inferioridade. Estamos falando aqui dos tempos que popularizavam a antropometria, a tecnologia de medir ossos, crânios e cérebros, que identificava nos corpos sinais tangíveis da inferioridade dos mais pobres (Coimbra \& Nascimento, 2003, cit. por Dameda, 2017).

Mello;Balaguer (1999;2005, cit. por Moreira \& Costa, 2016), seguindo a mesma linha de raciocínio quanto às contradições inerentes aos próprios exercícios do ECA, argumentam que antes da violência perpetrada por adolescentes infratores se verifica a violência estatal na privação de acesso aos seus direitos civis. Desconsiderado em relação às camadas mais pobres da população, o Estado priva-as dos direitos civis mais básicos, colocando-as na fronteira para além da cidadania.

De acordo com Moreira et al. (2015) no caso de adolescentes em conflito com a lei, sua segregação muitas vezes não está relacionada ao crime, mas à sua condição individual, o que reflete a falta de reconhecimento desses jovens pelo Estado e pela sociedade e, portanto, são referidos como criminosos e a dimensão política de sua existência é excluída.

Sob tais tensões, Segundo Moreira, Romagnoli, Melgaço, Dias e Bouzada (2014) os direitos das crianças e jovens podem ser obtidos por meio da subjetividade das normas e disciplinas, e essas normas e disciplinas são produtos de seu discurso e prática. As normas são pensamentos estruturados que receberam o 
status de verdade. Elas perpassam todos os eixos de poder e incentivam as pessoas a moldar e criar suas vidas.

Essas normas têm entrado no campo jurídico desde a classificação dos crimes, passando por fiscalizações de discursos sobre seus perigos e ilegalidades. Nos estudos analisados pelos autores, as regras responsabilizam o jovem e o internam. Portanto, é óbvio que as medidas socioeducativas ainda têm o caráter punitivo da Justiça Retributiva e não protegem o direito à defesa do jovem. Nesse caso, acreditamos que a relação entre poder e tensão condena a complexidade da prática pavimentada no ECA (Moreira et al., 2014).

Ainda segundo os autores, os meios de comunicação e os jornais são considerados os elementos de circulação padrão e o espaço de domínio e reprodução do sistema vigente, bem como os disseminadores da cultura aliada ao modelo capitalista. A mídia, principalmente sob a orientação da classe dominante, desempenha um papel fundamental no controle da sociedade: internalizando o controle e usando técnicas de observação como meio de impor padrões de comportamento/ideológicos. Portanto, não é surpreendente que os discursos de juízes brasileiros sobre punição de adolescentes infratores, famílias desestruturadas, psiquiatria e pobreza tenham sido respondidas na mídia.

É esse tipo de mídia com estereótipos discriminatórios e estigma que usa brechas do ECA para promover discussões sobre a redução da maioridade penal (Moreira et al., 2014).

\subsection{Redução da Maioridade Penal}

$\mathrm{Na}$ trajetória da pesquisa encontramos na página oficial da Câmara dos Deputados a Proposta de Emenda da Constituição PEC 171/1993 que tem como ementa a imputabilidade penal do menor de dezesseis anos inscrita na redação do art. 228 da Constituição Federal. Essa PEC ainda está em tramitação em que foi aprovada a Proposta de Redação para o Segundo Turno de Discussão e Votação, no ano de 2015.

Nessa discussão, o fato de o adolescente ainda ser um indivíduo em formação é totalmente excluído pelas palavras "ele já sabe o que está fazendo" apresentadas pelo senso comum. Esse jovem é também um conceito de direitos - negado novamente no caso dos jovens de baixa renda - e abandonado por punição, na qual é visto como uma pessoa "fora" da sociedade, o que a ameaça e, portanto, deve ser excluído (Moreira et al., 2014).

Os autores argumentam que essa visão é apoiada por notícias generalizadas de crimes cometidos por jovens, especialmente pessoas de baixa renda. Nas reportagens, os jovens infratores são sempre vistos apenas quando são perigosos e nunca os analisam subjetivamente. Portanto, é fácil propor como solução a prisão e a retirada desses jovens do convívio social, ignorando o que isso realmente significa: esses jovens entram prematuramente no sistema penitenciário falido de adultos.

Atualmente, considerando a ampla disponibilidade de informações, o desenvolvimento pessoal das crianças e adolescentes costumam ser anterior à década de 1940. Portanto, se a situação mudou, as regras precisam ser definidas para hoje. Outro argumento legal a favor da redução da maioridade penal é que, se os jovens com mais de 16 (dezesseis) e menores de 18 (dezoito), possam ter uma visão do futuro do país por meio do voto, de acordo com o artigo da Carta Magna [11] Art. 14 A letra c do item 1 e o inciso II, este último também pode distinguir atos criminosos, de forma que tenha a capacidade de discernimento entre o certo e errado e conhecer as consequências de seus atos (Oliveira, 2016). 
Mas todos esses adolescentes podem ser considerados precoces? Não acreditamos, especialmente aqueles que estão em um estado socialmente desfavorecido e que mais precisam de proteção legal. Desta forma, interpretamos a redução da idade penal como um erro. Esta política constitui um grande crime social porque coloca menores que cometeram crimes menores na prisão, aumentando assim o número de adultos marginalizados. Na verdade, há um grande número de crimes juvenis, e a maioria desses jovens está na classe mais vulnerável da sociedade. No entanto, a marginalização dessas pessoas não se limita às condições socioeconômicas, mas é o resultado de vários outros fatores, como desagregação familiar, alcoolismo dos pais, violência (física, sexual e moral), desemprego, entre outros. É preciso compreender que os adolescentes autores de atos infracionais, na sua maioria, provêm de situações de criminalização e exclusão social, permeadas pelo abandono, invisibilidade, processos de estigmatização, marginalização e, consequente, privação de liberdade (Marques, 2016).

Os saberes produzidos pelo diagrama da justiça retributiva, mesmo com a promulgação do ECA, atravessam as práticas de medidas socioeducativas na contemporaneidade. A realidade sendo esse palco de disputas entre os saberes/poderes, esses saberes/poderes coexistem e disputam a hegemonia com outros saberes/poderes como os que mostraremos a seguir no diagrama da justiça restaurativa.

Foucault (2008) nos mostra que no final do século XVIII, início do século XIX, emerge um novo tipo de poder, que não mais tem o objetivo de disciplina, mas de gerir os processos da vida e morte das populações, a biopolítica. Esse biopoder não substitui a disciplina, mas a integra, tecendo uma complexa rede de poder (Foucault, 2008). É dentro desse contexto que esboçamos o diagrama da Justiça Restaurativa, problematizando suas práticas, traçando linhas de fuga que possibilitam resistência e essa captura das subjetividades por meio das políticas públicas, nesse caso, das medidas socioeducativas.

\subsection{Diagrama da Justiça Restaurativa}

O Conselho Econômico e Social da Organização das Nações Unidas (ONU) publicou a Resolução 2002/12, que defina os princípios básicos e diretrizes para o uso de procedimentos da Justiça Restaurativa em matéria penal. Essa norma tem influenciado a adoção de procedimentos restaurativos em muitos países, incluindo o Brasil. Oficialmente, a implementação da Justiça Restaurativa no Brasil ocorreu no início de 2005, quando o Programa das Nações Unidas para o Desenvolvimento (PNUD) forneceu apoio financeiro para financiar o lançamento de três projetos piloto de Justiça Restaurativa, a saber, Brasília - DF, que foi convocado no Juizado Especial Criminal, de Porto Alegre - RS que se chamava Justiça do Século XXI voltada para a Infância e Juventude, e São Caetano do Sul - SP também para a justiça da Infância e Juventude (Carvalho, 2019).

A Justiça Restaurativa é baseada em um processo de consenso no qual a vítima e o agressor, e quando apropriado, outras pessoas ou membros da comunidade afetados pelo crime como o sujeito central, participam coletivamente e ativamente na construção de uma solução de restauração do trauma e perda causados pelo crime. Este é um processo estritamente voluntário e relativamente informal que envolve um ou mais mediadores ou coordenadores, e suas formas incluem mediação vítima-agressor, reuniões coletivas envolvendo familiares e membros da comunidade e o círculo de decisão (Pinto, 2010).

Em alguns estudos, como o de Gimenez e Spendler (2018) e de Santos (2017) podemos observar práticas restaurativas que tinham como plano de 
intervenção, a resolução de conflitos, ao lado da mediação e de outras múltiplas ferramentas. Esses encontros são pautados em valores como a voluntariedade, responsabilidade, verdade e empoderamento que tem como objetivo o reparo dos danos, solução do conflito ou a conciliação/reconciliação.

Há também a adoção dessas práticas na execução das medidas socioeducativas como vistos nos estudos de Gimenez e Spendler (2018) que ressaltam atender ao artigo $3^{\circ}$ do Estatuto da Criança e do Adolescente pois:

Permite que todo
adolescente goze de todos os direitos fundamentais inerentes à pessoa humana, sendo-lhe asseguradas todas as oportunidades e facilidades, a fim de lhes facultar o desenvolvimento físico, mental, moral, espiritual e social, em condições de liberdade e de dignidade (Gimenez \& Spendler, 2018, p. 245).

Foucault mostrou em "O Nascimento da Biopolítica" (2008) que com o surgimento do neoliberalismo, uma nova racionalidade de governo emergiu. Especificamente, o liberalismo americano não é apenas uma tecnologia governamental ou uma escolha econômica e política. Esta é uma forma de ser, pensar, analisar e imaginar, ou seja, é uma relação entre o governante e os governados.

Ao mesmo tempo, Foucault (2010, citado por Benevides \& Prestes, 2014) descreveu como a população se tornou simultaneamente objeto e sujeito de uma nova tecnologia de poder. Essa nova tecnologia por sua vez passou a focar nos processos da vida, como ferramenta básica para fortalecer o próprio capitalismo, sem comprometer o domínio da população. Desse modo, esses mecanismos de poder terão a função de produzir um sujeito forte e saudável, ao mesmo tempo em que terão a função de serem dóceis, fáceis de obedecer e manejar.

Considerando que as práticas restaurativas são pautadas em valores como voluntariedade, responsabilidade e empoderamento, valores que se tornam relevantes em um determinado momento histórico, quais as condições de sua emergência? Seriam essas novas práticas, novas formas de captura e governo dos sujeitos nelas inscritos e qual o papel da psicologia nessa política? Já alertados por Deleuze (1995) que um dispositivo também é composto por linhas de fuga, quais as possibilidades de resistência e singularização nesse dispositivo?

\subsection{Governamentalidade e Práticas Psicológicas}

A governamentalidade moderna não é apenas uma relação de obediência, mas também um movimento de participação subjetiva. As leis estão cada vez mais funcionando como normas e as instituições judiciais estão cada vez mais integradas a um contínuo de instituições (médicas, administrativas, etc) nas quais as funções principais são reguladoras. Uma sociedade normalizada é o resultado histórico de uma tecnologia de poder centrada na vida (Foucault, 2010, p. 157, cit. por Bevenides \& Prestes, 2014).

As próprias políticas públicas que irão surgir no Brasil juntamente com a psicologia podem ser compreendidas como tecnologia de poder, ou seja, têm a função de acompanhar de perto as crianças e adolescentes, emoldurando seu campo de ação, agindo sobre elas, trabalhando com as estatísticas, como o aumento da probabilidade do sujeito de fazer determinadas escolhas, produzindo capital humano, um sujeito neoliberal, que é útil ao mercado. 
Diante desses preceitos sobre a governamentalidade, relacionamos os valores prescritos nas práticas restaurativas como sendo uma parte subjetiva do sujeito, nos quais os profissionais envolvidos neste trabalho de socioeducação e ressocialização principalmente os psicólogos, são os grandes responsáveis pela promoção de valores, atitudes e identidades.

No Brasil, pode-se observar na Constituição de 1988, como cita Gallo (2020) em seus estudos, uma nova forma de constituição estava sendo formada que tinha como reconhecimento os direitos civis e a cidadania, que eram seus pilares principais. Com a promulgação da constituição surgiram novas formas de políticas públicas e essas enquanto governamentalidade biopolítica, preocupa-se com as questões populacionais como: a cidadania dessa população, a relação dessa população com a economia, o mercado de trabalho, a seguridade social, a saúde e a educação.

A governamentalidade como um conjunto de instituições que exerce poder a uma determinada população, envolve a Psicologia como uma ferramenta de promoção dos direitos legais previstos no ECA em relação às crianças e adolescentes. Um estudo realizado pelo Conselho Federal de Psicologia e o Centro de Referência Técnica em Psicologia e Políticas Públicas (Nascimento, Brigagão, Bichara, Aragaki \& Spink, 2009) relataram as práticas dos psicólogos no contexto das medidas socioeducativas em unidades de internação. As práticas realizadas são: atendimento psicológico individual (com o jovem, a família), coletivos (grupos terapêuticos, operativos e temáticos), atuação em equipe multidisciplinar, entre outros. Essas práticas têm como objetivos a psicoterapia focal e breve, acompanhamentos dos casos, acolhimento, intervenções individuais e grupais, em crises/conflitos interpessoais, visa a troca de informações sobre o jovem, o acompanhamento e observação do jovem nas atividades internas, aplicação de medidas disciplinares. $\mathrm{O}$ atendimento com a família propicia o acolhimento no ingresso dos(as) jovens na instituição, a compreensão dos valores, o estreitamento dos laços familiares e a cidadania.

De acordo com Ferreira, Santos, Monteiro e Fonseca (2019) o aprofundamento da relação entre as formas de governo e a psicologia, há uma conexão entre a prática psicológica e a arte do governo de uma dupla forma: por meio da tecnologia de inscrição, tornando a subjetividade disponível para a tecnologia de governo; por meio da formulação de múltiplas políticas, não só destinadas a orientar o comportamento individual, controle, disciplina e regulação, mas principalmente por meio de sua liberdade e atividades. Nesse contexto, as práticas psicológicas podem ser entendidas como tecnologias de poder, capturando a vida afim de produzir sujeitos torná-los mais inteligentes, empreendedores, dóceis, produtivos e dotados de autoestima.

O foco mudou de questões territoriais para questões populacionais, da gestão de recursos para a gestão do poder sobre a vida (ou seja, biopoder), de ameaças externas ao Estado para riscos internos relacionados à população (Fimyar, 2009, p. 37, cit. por Armiliato, 2013).

É a partir dos procedimentos de totalização (supervisão biopolítica) e individualização (padronização disciplinar) que a racionalidade política, como o liberalismo moderno e o neoliberalismo contemporâneo, podem ser entendidos como técnicas de governança (Candiotto, 2011, p. 471, cit. por Armiliato, 2013).

Como forma de intervenção racional no exercício do poder político dos homens, o papel da polícia é dar-lhes um pequeno suplemento em suas vidas, e isso é dar mais poder ao Estado (Foucault, 2006, p. 379, cit. por Armiliato, 2013). 
O objetivo da arte moderna é a gestão ou racionalidade nacional: desenvolver esses elementos da vida pessoal de forma que seu desenvolvimento também fortaleça o poder do Estado (Foucault, 2006, p.383, cit. por Armiliato, 2013).

O poder como jogo estratégico é uma característica universal da interação humana, pois significa construir campos de ação possíveis para os outros. Isso pode assumir muitas formas (por exemplo, manipulação ideológica ou argumentação racional, conselho moral ou exploração econômica), mão não significa necessariamente que o exercício do poder em uma relação de poder seja contra os interesses da outra parte, nem tampouco significa necessariamente que "decide o comportamento da outra parte" e que o "outro" é essencialmente "mau". Além disso, as relações de poder nem sempre resultam na privação da liberdade ou escolha disponível do indivíduo. Ao contrário, no sentido de Foucault, o poder pode levar ao "empoderamento ou "responsabilidade", obrigando-os a tomar decisões "livres" no campo de ação (Lemke, 2017).

\subsection{Medidas Socioeducativas e as Possibilidades de (Re) existência}

Considerando a alternativa de que há algo de positivo no poder, por meio da governamentalidade surgem possibilidades de singularização e resistência, como a possibilidade de o sujeito de se tornar protagonista e fazer algo novo. Isso nos permite traçar e apresentar possíveis linhas de fuga, no que se refere as medidas socioeducativas as quais consistem em: advertência, responsabilidade pela reparação de avarias, serviço comunitário, liberdade assistida e semiliberdade. Medidas essas que vão de encontro ao que é proposto na justiça restaurativa. Justiça esta que está em contraposição ao modelo retributivo da justiça criminal.
Ao mapear artigos que apresentam novas perspectivas para a aplicação das medias socioeducativas no Brasil, nota-se que as práticas têm como referência e justiça restaurativa.

Nos estudos de Gimenez e Spendler (2018) é proposto que a justiça restaurativa como instrumento de humanização da execução de medidas socioeducativas no Brasil, a qual encontra guarida na legislação pátria, bem como cumpre com o fundamento do Estado Democrático de Direito, qual seja, a dignidade da pessoa humana. A adoção das práticas restaurativas na execução das medidas socioeducativas, conforme verificado acima, contribui para a construção de um novo modelo de justiça criminal, o qual busca, a partir do diálogo, a participação de todos os envolvidos no ato infracional, inclusive a vítima, a auxiliar na reparação do dano e na restauração das relações atingidas pela prática delitiva.

A adoção das práticas restaurativas para a execução das medidas socioeducativas atende ao artigo $3^{\circ}$ do Estatuto da Criança e do Adolescente (Lei n ${ }^{\circ}$ 9.069/90), pois permite que todo adolescente goze de todos os direitos fundamentais inerentes à pessoa humana, sendo-lhes asseguradas todas as oportunidades e facilidades, a fim de lhes facultar o desenvolvimento físico, mental, moral, espiritual e social, em condições de liberdade e de dignidade.

Nos estudos de Santos (2017) encontramos propostas da justiça restaurativa com o intuito de diminuição dos danos e transtornos causados pela pena, utilizando como elemento ressocializador e restituição criativa além do princípio da voluntariedade (infratorvítima). Este estudo tinha como atravessamentos a restauração das relações sociais (familiares e na comunidade), políticas públicas de inter-relação da família na comunidade e construção social. Apresentando a justiça restaurativa como novo modelo para tentar combater a reincidência. 


\section{CONSIDERAÇÕES FINAIS}

Atualmente ainda nos deparamos com uma máquina estatal e justiça penal permeados por preceitos da justiça retributiva. Políticas públicas, investimentos e práticas visam a culpabilidade e punição, uma vez que o intuito deveria buscar práticas mais humanizadas e ressocializadoras. Durante os estudos, percebemos que apesar do avanço das políticas públicas, as práticas continuam atadas às técnicas individualizantes e a projetos terapêuticos que não consideram a integralidade dos envolvidos e multifatorialiade dos casos, que não irão suprir todas as demandas e necessidades das crianças e adolescentes, fatores esses que têm como consequência o aumento nos índices de reincidência.

Os desafios da prática profissional de psicologia ainda deverão ser enfrentados, é necessário que os profissionais olhem para além da burocracia executiva. Requer que o psicólogo(a) tenha uma visão holística em relação aos envolvidos. Atuando de maneiras que considerem e respeitem a individualidade e Subjetividade, contribuindo para que as medidas socioeducativas se tornem mais eficazes e efetivas, propiciando práticas mais humanizadas e ressocializadoras.

\section{REFERÊNCIAS}

Armiliato, V. (2013). Políticas sociais: estratégias de governamentalidade. Sociologias Plurais, 1(2), 248-270.

Benelli, S. J. (2014). Foucault e a prisão como modelo institucional da sociedade disciplinar. A lógica da internação: instituições totais e disciplinares (des) educativas [online] (pp. 63-84). São Paulo: Editora UNESP.

Benevides, P. S., \& Prestes, T. K. A. (2014). Biopolítica e governamentalidade: uma análise da Política Nacional sobre Drogas. ECOS-Estudos Contemporâneos da Subjetividade, 4(2), 274-287.
Brasil. (2012). Lei no 12.594, de 18 de janeiro de 2012. Institui o Sistema Nacional de Atendimento Socioeducativo (Sinase), regulamenta a execução das medidas socioeducativas destinadas a adolescente que pratique ato infracional; e altera as Leis ${ }^{\circ}$ s 8.069 , de 13 de julho de 1990 (Estatuto da Criança e do Adolescente); 7.560, de 19 de dezembro de 1986, 7.998, de 11 de janeiro de 1990, 5.537, de 21 de novembro de 1968, 8.315, de 23 de dezembro de 1991, 8.706, de 14 de setembro de 1993, os Decretos-Leis nos 4.048, de 22 de janeiro de 1942, 8.621, de 10 de janeiro de 1946, e a Consolidação das Leis do Trabalho (CLT), aprovada pelo Decreto-Lei ${ }^{\circ} 5.452$, de $1^{\circ}$ de maio de 1943. Diário Oficial da União.

Cardoso, I. D. A. R. (1995). Foucault e a noção de acontecimento. Tempo social, 7(1-2), 53-66.

Carvalho, A. N. (2019). Justiça restaurativa e a trajetória da sua implementação no Brasil: uma observação das experiências nacionais. Conteído Jurídico, Retirado de: https://conteudojuridico.com.br/consulta/Ar tigos/53042/justica-restauratica-e-a-trajetoriada-sua-implemntacao-no-brasil-umaobservacao-das-experiencias-nacionais. Acesso em: 06 jun 2021.

Conselho Federal de Psicologia. (2010). Referências técnicas para atuação de psicólogos no âmbito das medidas socioeducativas em unidades de internação. Brasília, DF.

Dameda, C. (2017). Adolescência e ato infracional: cartografia de processos de subjetivação de adolescentes em medida de liberdade assistida. (Dissertação de mestrado). Retirado de http://www.uniedu.sed.sc.gov.br/

Deleuze, G. (2014). El poder: Curso sobre Foucault, tomo II (Buenos Aires: Cactus).

Domingos, B. (1993). PEC 171/1993. Altera a redação do art. 228 da Constituição Federal (imputabilidade penal do maior de dezesseis anos). Câmara dos Deputados.

Ferreira, A. A. L., Santos, M. V. D. A. G., Monteiro, G. G., \& Fonseca, L. E. P. D. (2019). Governamentalidade e práticas psicológicas: modos de gestão nos artigos brasileiros de psicologia do trabalho (1949 a 1965). Arquivos Brasileiros de Psicologia, 71(3), 64-87. 
Filho, J. R. A. (2015). Prisão, delinquência e subjetividade. ECOS-Estudos Contemporâneos da Subjetividade, 5(2), 161-170.

Filho, K. P., \& Teti, M. M. (2013). A cartografia como método para as ciências humanas e sociais. Barbarói, (38), 45-59.

Foucault, M. (1987). Vigiar e punir: nascimento da prisão. $20^{\circ}$ Edição. Editora vozes, Petrópolis.

Foucault, M. (2008). Nascimento da biopolítica curso dado no College de France (1978-1979). Traduzido por Eduardo Branda. São Paulo: Martins Fontes.

Frota, A., M. M. C. (2007). Diferentes concepções da infância e adolescência: a importância da historicidade para sua construção. Estudos e pesquisas em psicologia, 7(1).

Gallo, A. E. (2008). Atuação do psicólogo com adolescentes em conflito com a lei: a experiência do Canadá. Psicologia em estudo, 13(2), 327-334.

Gimenez, C. P. C., Spengler, F. M. (2018). A justiça restaurativa como instrumento de fortalecimento da cultura de paz. Políticas públicas e boas práticas para o sistema penal, 8(1), 244-259.

Guattari, F., \& Deleuze, G. (2011). Mil platôs [1995] (pp. 1-18). Tradução de Aurélio Guerra Neto e Célia Pinto Costa, v. 1. Rio de Janeiro: 34.

Guerra, A. M. C., Cunha, C. D. F., Costa, M. H., \& Silva, T. L. (2014). Risco e Sinthome: a psicanálise no sistema socioeducativo. Psicologia: teoria e pesquisa, 30(2), 171-177.

Hüning, S. M., Bernardes, A. G. \& Reis, C. (2019). Psicologia, Territorialidades e Violências. Psicologia: Ciência e Profissão, 39(spe2), e042019. Epub November 14, 2019.https://doi.org/10.1590/1982$\underline{3703000042019}$

Kontoyanis, L. D. (2018). A justiça restaurativa em tempos de "crise" do sistema de justiça criminal: uma proposta de reinserção social. UniCEUB, Brasília.
Lazzarotto, G. D. R. (2014). Medidas socioeducativas: cartas ao reinado do saber. Psicologia em Estudo, 19(3), $503-$ 514. https://dx.doi.org/10.1590/1413$\underline{73725000313}$

Lemke, T. (2017). Foucault, governamentalidade e crítica. Traduzido por Eduardo Altheman Camargo Santos. PLURAL, 24.1, 194-213.

Marques, F. F. S. (2016). Redução da maioridade penal. Retirado de https://jus.com.br/artigos/49851/reducaoda-maioridade-penal.

Moreira, J. O. \& Costa, D. B. (2016). ECA: entre o desenvolvimento teórico e o subdesenvolvimento prático. Moreira, J. O., Salum, M. J. G. \& Oliveira, R. T. (Orgs.). Estatuto da crianca e do adolescente: refletindo sobre sujeitos, direitos e responsabilidades $1^{\circ}$ edição (pp. 46-59). Brasília: CFP.

Moreira, J. O., Guerra, A. M. C., Oliveira, N. A., de Souza, J. M. P., \& Soares, C. A. N. (2015). Medidas socioeducativas com seus dispositivos disciplinares: o que, de fato, está em jogo nesse sistema? Revista Psicologia Politica, 15(33), 285-302.

Moreira, J. O., Romagnoli, R. C., Melgaço, P., Dias, A. F. G., \& Bouzada, G. C. F. (2014). A medida socioeducativa de internação sob uma lente foucaultiana. Revista Polis e Psique, 4(1), 73.

Nascimento, V. L. V., Brigagão, J. I. M., Bichara, T. A. C., Aragaki, S. S. \& Spink, P. K. (2009). A prática profissinal dos(as) psicólogos(as) em medidas socioeducativas em unidades de internação. Conselho federal de psicologia, 44 p.

Oliveira, J. (2016). A redução da maioridade penal à luz do minimalismo. Retirado de https://jus.com.br/artigos/53115/a-reducaoda-maioridade-penal-a-luz-do-minimalismo

Pinto, R. S. G. (2010). A construção da Justiça Restaurativa no Brasil. Revista Paradigma, (19). 
Santos, A. G. S. (2017). Alternativas de reintegração do menor infrator por meio da medida socioeducativa. Ambito Jurídico, (159), Ano XX.

Santos, E. P. S. (2011). Desconstruindo a menoridade: a psicologia e a produção da categoria menor. Psicologia Jurídica no Brasil, 3, 43-72.

Segalin, A., \& Trzcinski, C. (2006). Ato infracional na adolescência: problematização do acesso ao sistema de justiça. Textos \& Contextos (Porto Alegre), 5(2), 1-19.

Zambenedetti, G., \& Silva, R. A. N. D. (2011). Cartografia e genealogia: aproximações possíveis para a pesquisa em psicologia social. Psicologia \& Sociedade, 23(3), 454- 